as far as possible to place before you simple facts; trusting that in estimating their significance you will be ever guided by that which our dear master has so constantly striven to inculcate as our leading principle-the love of truth."

When I compare the surgery of my student days with the furgery of to.day the outstanding jmpression on my mind is the amount of physical suffering which Lister has saved the human race. It is, in my opinion, incalculable. We hear often of lives and limbs saved; to my mind the pain saved is even more striking. Ansesthesia saved pain during, asepsis after, an operation.

From first to last Lister's aim in Glasgow, Edinburgh, and in London has been to obtain if possible. a method whereby open wounds would follow the painless and safe course of a subcutaneous wound, in other words, follow an aseptic course. I sincerely trust that I have said nothing that will for a single moment give my dear master a passing thought that these reminiscences of past days had been better unsaid. Gertainl. I feel that they could have been better said, but I trust they may be looked upon simply as an expression, however incomplete, of the love and loyalty of a pupil for his master, and in no sense as an adequate record of Lister's work in Edinburgh.

\section{LISTERISM AND THE DEVELOPMENT OF OPERATIVE SURGERY.}

By W. Watson Cheyne, F.R.C.S., F.R.S., Senior Surgeon to King's College Hospital and and Professor of Clinical surgery in King s College.

UURING the winter session 1872.73 I first took out the course of clinical surgery at the University of Edinburgh, and there became acquainted with the subject of antiseptic surgery. Like many other Edinburgh students, I very soon became much fascinated with the work, not only with the actual healing of the wounds but even more with the enormous possibilities which were daily opening out under the protection of this treatment. During that time we constantly saw things done in the way of operative interference which were not in the books, or, if referred to, were spoken of as more or less unjustifiable procedures, and the consequence was that we watched these results with the very greatest interest. In fact, what went on in the Listerian wards was one of the chief topics of conversation among the students, and the classes were very largely attended and were most enthusiastic.

In the great importance of the revolution in wound treatment one is apt to lose sight of the fact that Lord Lister was also the pioneer in many of the modern operative procedures. Not only was he constantly employed in experiments and observations on wound treatment, and in improving and simplifying the methods according to experience and the advances of scientific knowledge, but he was also constantly engaged in modifying and developing various surgical procedures in the treatment of individual patients in reliance on the protection against sepsis afforded by this method. The same thought and ingenuity were brought to bear on the remedying of deformities and the treatment of disease as on the question of the avoidance of infection and suppuration of the wounds, and it was there that the chief attraction of his wards lay. As a matter of fact. Lord Lister looked on these new procedures as natural developments of the method of wound treatment employed; and, unfortunately, very little of his actual surgical work has been published.

I was so fascinated with his lfctures and work that I took copious notes of everything that passed at the lectures, and I look on my notebook of clinical lectures for the sessions 1872 and 1873 as one of the most valuable possessions I have. On referring to these notes I find records of a number of cases which show the advanced state of surgical treatment in his wards at that time, and I may briefly refer to a few of these.

There were, for example, a number of operations on bones. There was a case of ununited fracture of the olecranon with considerable disability of the arm, where the part was cut down upon, the fibrons tissne removed from between the fragments, and these wired together with silver wire. With regard to this case, $I$. have the note that " the after-progress was satisfactory, and the man left the infirmary with a freely movable elbow as useful as the other." I also.find notes of cases of ununited fracture of the radius and of ununited fracture of the femur treated with success by free incision and wiring of the fragments, and there are cases of exostosis freely cut away, in opposition to the teaching which we received elsewhere, that unless these growths were cansing very serious trouble they should not be touched, and that if touched some form of subcutaneous division should be einployed. There is akso a case of chronic periostitis and osteitis of the femur where the bone was cut down upon and portions removed by chisel and hammer, a method of treatment which in suitable cases has not been improved on up to the present time.

Then we had cases of scirrhus of the breast, where extensive operations were done with the view of removing the axillary contents, in some cases the pectoral muscles being divided so as to obtain complete access to this region. The operations then done were in fact as complete as any that have been performed up till recent times.

We had cases of psoas abscess treated by free incision and drainage, with the result that healing took place without suppuration or hectic fever, although naturally the treatment lasted for a very considerable time.

Then we had such smaller procedures as incision of a large haematoma, where the clot, instead of being absorbed, had developed into a blood cyst, and where, in opposition to the teaching of those days, an incision was made into the collection, a drainage tube introduced, and the wound healed up without any trouble. Similarly we bad a case of housemaid's knee successfully treated by the introduction of a drainage tube-a procedure which at that time was also looked on as unwarrantable.

Perhaps the most interesting case which occurred during that winter session was one of suprapubic lithotomy. Some extremely interesting lectures were delivered on the treatment of calculus in the bladder, in which Lord Lister, after describing the methods of performing perineal lithotomy and the dangers accompanying them, took up the subject of suprapubic lithotomy. He referred to the work of Cheselden axd others, and pointed out that what had been done in this direction seemed to show that the chief danger of the high operation lay in the occurrence of suppuration from extravasation of the urine, while he referred to the great advantages which might follow suprapubic cystotomy as compare with operations through the perineum. He further pointed out that, unless urine is septic, it is a bland fluid, and that with antiseptic treatment the great objection to this operation might be removed. On November $28 \mathrm{th}, 1872$, he operated on a boy, aged 14, by the suprapubic method. The boy had suffered from symptoms of stone for eight years, and was in a very pitiable condition, and no doubt his bladder was considerably contracted. However that may be, in cutting down on the bladder the peritoneum was opened, but after consideration Lord Lister stitched up the opening in the peritoneum and completed the suprapubic operation. A large stone was removed, and the opening in the bladder wall was stitched up with catgut, these stitches being used as they are at the present time so as not to include the mucous membrane. No peritonitis followed the operation, the wound in the bladder remained perfectly firm, the boy passed water naturally, and in the course of about a couple of days was able to retain it for four hours. He completely recovered, although I should think from the description of the case that some slight sepsis did occur in the superficial wound : at any rate the superficial stitches gave way, and the wound bealed by granulation. This case is extremely interesting, as it was really the commencement of the new era of suprapubic cystotomy, although it was not till a good many years afterwards that this operation was recognized as one of the best methods of obtaining access to the bladder. Had this case and the arguments in favour of the procedure been published at the time it is practically certain that Lister's name would have been associated with the modern reintroduction of suprapubic cystotomy.

Many other procedures were adopted which were also in advance of the times. We had cases-not apparently during 
this session, but while I was still a student-where deformities of the bones, such as knock-knee, curved tibiae, malunited fractures, etc., were treated by osteotomy, in some instances with the removal of suitable wedge-shaped portions of bone. Incisions were also made freely into joints for the removal of loose cartilages or in the case of tuberculous joints with the idea of relieving tension. Radical cure of hernia had already been attempted by stitching together the walls of the canal, or at any rate of the rings. Naevi were excised when necessary, and I find in my notebook a case of piles treated by injection of carbolic acid-a method of treatment which was a good deal later brought into considerable prominence.

When it is remembered that these operations, and many others to which I might refer, were performed in 1872 , and that they were at that time looked on by other surgeons as unjustifiable procedures-if, indeed, they had been thought of at all-we see how far in advance of his time Lord Lister was, not only as a scientific but also as a practical surgeon, and I think that my contention will be readily admitted that his name should be remembered not merely as the discoverer of asepsis in wounds, but as the pioneer of many of the modern surgical operations which are now daily performed.

With regard to the method of treating wounds at that time, Lord Lister had just given up the use of lac plaster and during that session he was employed in experimenting with gauze impregnated in various ways, leading ultimately to the carbolic gauze dressing which was used aiterwards for several years. It was about that time that he first introduced the use of the spray. I remember hearing him lecture-I think it was in the introductory lecture in that session-on the methods of avoiding contamination from the air, in which he discussed various plans, such as operating under a bath of an antiseptic, or employing continued irrigation of the wound, or the use of a fine spray of carbolic acid and he decided on the latter because there would be the least irritation of the cut surfaces He referred more than once to the great importance of avoiding the irritation of cut surfaces with the antiseptic pointing out that the object of these antiseptics was to kill things before they got into the wound, and that the further aim of treatment was to keep them out of the wound as much as possible so as to leave the healing of the wound itself to Nature ; with this aim he introduced the oil-silk protective. Drainage was at that time constantly employed, but in his lectures he refers to attempts to get rid of the drainage tube by the employment of sponge pressure, and he also there refers to the possibility of stitching together the deeper parts of the wound with catgut. In the treatment of ulcers he was at that time very enthusiastic in the employment of Reverdin's method of epidermis grafting and during that session. I also find the first mention of boracic acid and boracic lint as a method of treating superficial wounds.

At that time the scientific basis on which the Listerian system was founded was still very crude. Septic conditions were looked on as essentially of a putrefactive nature, and when putrefaction was absent sepsis was looked on as also absent. But even at that time, and before I had completed my studentship, Lord Lister was beginning to conclude from his operative work and the observations made on his wounds, that this was too narrow a generalization, and that these micro-organisms must be of a great variety of species, and that the association of putrefaction was not essential to even the most serious forms of sepsis. He was coming to the conclusion that different species of organisms must be accountable for different septic diseases, and I well remember his timidly putting forward the view that even tetanus was probably due to an organism, because he had not had a case of tetanus for many years, although previously it was quite a common disease. Lord Lister himself probably provided the first complete demonstration of the existence of distinct species of organisms in his researches on lactic fermentation, where he was able by a very ingenious device to separate a single organism, the bacillus lactis, which produced this fermentation and no other.

At the commencement of 1877 Lord Lister was invited to take up the duties of Professor of Clinical Surgery in King's College, London, and Surg on to the hospital. After much consideration and hesitation he at length acceded to the request in the hope that in the larger centre he would be able to spread his views more quickly. He delivered his introductory lecture
" On Lactic' Fermentation" at King's College, on October Ist, 1877. The treatment of wounds was at that time in a very backward condition in London. Some surgeons were using carbolic acid and two or three were employing the Listerian methods, but there was nothing like a general adoption of the principles or practice. I was acting as Lord Lister's housesurgeon in Edinburgh when he received the invitation to go to London, and he asked me to accompany him and act as his first house-surgeon at King's College Hospital. I well remember very shortly after coming to London being asked by a late well-known surgeon to help him to perform an amputation antiseptically. I had no great difficulty in keeping him right as regards disinfection of hands, instraments, etc. I could not, however, succeed in persuading him to cut his ligatures short. Nothing would induce him to believe that a ligature could be applied around a vessel and not be extruded from. the wound subsequently. Accordingly he left a number of silk ligatures hanging out of the stump and long after the rest of the wound was firmly healed these ligatures were holding as firmly as: ever. It was very amusing to see the surgenn daily trying to get away the ligatures till ultimately they had to be cut as short as possible and the wound allowed to close over them. Needless to say he always cut his ligatures short afterwards.

Perhaps the most striking illustration of the backward state of matters was the want of enthusiasm in the students as a whole as contrasted with those in Edinburgh. The explanation was the enormous influence which examining bodies have over the education of the student. At that time several of the examiners were actively opposed to the Listerian prin (iplt 8 , while others did not realize the change which they had already produced in surgical practice. Consequently the students, rightly or wrongly, came to the conclusion that they would be more likely to pass their examinations if they adhered to the old teaching, and they looked on Lord Lister's lectures as of the nature of post-graduate courses which the $y$ had better not attend till after they had become quali-fied.

When Lord Lister came to London he was still using carbol-ized gauze, oil-silk protective, carbolic spray, etc., but he wasas before ever on the search for improvements, and was continually advancing with the advance of scientific knowledge; theaim which he had constantly before him was the simplification of his methods and the avoidance of irritation of the wounds by: the substances employed. Hence, at a later period, when corrosive sublimate was demonstrated to be a good antiseptic, he experimented very largely on its uses in surgery, and introduced a variety of gauzes, wools, etc., impregnated with various preparations of marcury, such as corrosive sublimate, mercury biniodide, etc., till he ultimately produced the dressing which is still largely used by many-namely, gauze impregnated with the double cyanide of mercury and zinc. He also steadily diminished the introduction of antiseptics into the wuunds themselves, and from the time that weak solutions of corrosive sublimate were introduced he ceased to bring carbolic acid in contact with the wounds, reserving it for the disinfection of the instruments and skin. Ultimately, when it was shown that. the dust in the atmosphere contained essentially non-pathogenic organisma, and might therefore be disregarded in its. effects on wounds, and also that the carbolic spray was ineffectual as a means of destroying the organisms in dust, he readily abandoned the spray. Indeed, for years he had been hoping to be able to do so, but had hesitated till the demonstration of the above facts was complete. These are the keynotes to all his later work on wound treatment, namely, attempts to get rid of all irritating antiseptics, to avoid the contact of antiseptics with the wounds as far as possible, and to find antiseptics which, if they do happen to come into contact with the wound, shall not irritate it. Indeed, the methods. of treatment which are 80 much in fashion at the present time, the 8o-called aseptic methods, are simply continuations of Lister's work, and are the completion of the aim which heheld before him. How far they are the most practical methods for general employment, or as useful as some admixture with." the Listerian methods, that is to say, the limited use of antiseptics, is a question which is quite open to debate; but they are in no way a departure from or improvement on the principle which Lister was constantly striving to carry out. 